\title{
ARTESANIAS SOBRE AS MODALIDADES DE CRER E DE PERTENCER: Entre questões antigas e recentes, uma trajetória na Antropologia e Sociologia da Religião
}

\section{Craftmanships on modalities of believing and belonging: among old and new issues, a trajectory in Anthropology and Sociology of Religion}

Daniel Alves ${ }^{1}$

\begin{abstract}
Resumo. Por motivos relacionados à linguagem própria e às condições de felicidade no mundo acadêmico, expressam-se de uma forma impessoal os assuntos relacionados ao conhecimento de como se conhece, ou "epistemologia". A antropologia, ou pelo menos parte dos que a realizam, ao dedicar-se ao processo do conhecimento de outros, reiteradamente levantou questionamentos epistemológicos em relação ao modo como a ciência e a filosofia ocidentais compreende-se a natureza, os eventos, o tempo ou o espaço. Não raras vezes, essas dúvidas foram expressas de modo bastante pessoal, trabalhando-se a partir do ponto de vista do outro por sobre o ponto de vista do sujeito que observa. Aqui realço alguns questionamentos por sobre a minha biografia acadêmica, mostrando como em determinados momentos foi necessário retrabalhar reflexivamente conceitos oriundos da academia ou das experiências de vida para compreender dados e situações concretas e complexas nas relações entre religião e sociedade. Mais ao final, explicito alguns limites específicos relacionados ao campo das interfaces entre religião, consumo e mídia.
\end{abstract}

Palavras-chave: biografia acadêmica, reflexividade, pesquisa, religião, consumo.

Abstract. For reasons related to the proper language and the conditions of happiness in the academic world, matters related to the knowledge of how to know, or "epistemology", are expressed in an impersonal way. Anthropology, or at least part of those who carry it out, by dedicating itself to the process of knowing others, has repeatedly raised epistemological questions regarding the way in which the Western science or philosophy understands nature, events, time or space. Often, these doubts were expressed in a very personal way, working from the point of view of the other over the point of view of the subject who observes. Here I highlight some questions about my academic biography, showing how at certain times it was necessary to reflexively rework concepts from the academy or life experiences to understand data and concrete and complex situations in the relations between religion and society. More to the end, I explain some specific limits related to the field of interfaces among religion, consumption and media.

Keywords: Academic biography, reflexivity, research, religion, consumption.

[O trabalhador intelectual] deve aprender a usar a experiência de sua vida no seu trabalho continuamente. (...) Dizer que pode

"ter experiência" significa que seu passado influi e afeta o

\footnotetext{
${ }^{1}$ Professor associado no Instituto de História e Ciências Sociais da Universidade Federal de Goiás, Regional Catalão (Universidade Federal de Catalão em implementação). E-mail: danalves1978@yahoo.com.br REVISTARELEGENSTHRÉSKEIA - 2019 - UFPR
} 
presente, e que define sua capacidade de experiência futura.

Como cientista social, ele terá que controlar essa interinfluência bastante complexa, saber o que experimenta e isolálo; somente dessa forma pode esperar usá-lo como guia e prova de suas reflexões, e no processo se modelará como artesão intelectual.

(WRIGHT MILLS, 1975, p. 212)

Este artigo visa retrabalhar certos temas de meu interesse em face de minha trajetória de pesquisa. A produção de um texto como o que apresento aqui permite um levantamento de linhas de pensamento gerais que, embora me acompanhem por anos, não foram evidenciadas a cada texto que produzi como autor ou co-autor. Tais linhas refletem algo de minha experiência de vida, e até o presente momento exercem papel fundamental no que Wright Mills, no texto citado na epígrafe, chama de artesanato intelectual. Por isso, procuro temas transversais que foram se constituindo ao longo da produção intelectual, para ao final apontar limites epistemológicos do meu interesse de pesquisa mais intenso atualmente: as relações entre religião, sociedade, consumo e materialidades.

\section{Reconsiderando, retratando e retrabalhando questões}

Minha trajetória é comum a outros estudantes beneficiados pela implementação do sistema de pós-graduação no Brasil desde o fim da década de 1960, e pelo sistema de fomento à pesquisa por bolsas de estudos individuais e por incentivo aos grupos de pesquisa, encabeçado pelo CNPq, pela CAPES e pelas demais agências de fomento em nível estadual. Graças a toda essa estrutura institucional, foram-me concedidas sucessivas bolsas a cada etapa de titulação ${ }^{2}$, sempre vinculadas a um orientador e a um núcleo de pesquisa. Participei ativamente, como aluno, da constituição inicial do núcleo de pesquisa ao qual estou vinculado hoje como pesquisador associado.

Logo que entrei no curso de Ciências Sociais, já no segundo semestre, atuava como pesquisador voluntário em um projeto sobre peregrinações e turismo religioso no Rio Grande do Sul (RS) junto ao professor Carlos Alberto Steil (PPGAS-UFRGS). Em 1998, foi-me concedida bolsa de Iniciação Científica, a qual me acompanhou durante toda a trajetória na graduação. O projeto ao qual estava vinculado tinha como primeiro objetivo mapear no Estado do Rio Grande do Sul romarias ligadas ou não à Igreja Católica, concentrações massivas de religiões afrobrasileiras, médiuns espíritas que recebiam

\footnotetext{
${ }^{2}$ Na graduação; Bolsa de Iniciação Científica do CNPq, no mestrado, bolsa CAPES; e no Doutorado; bolsa CNPq.

REVISTARELEGENSTHRÉSKEIA - 2019 - UFPR
} 
milhares de pessoas para tratamentos espirituais e projetos turísticos vinculados a simbologias religiosas. Depois de tal mapeamento, passamos a fazer estudos de casos diversos. Analisamos naquele momento as mediações de simbologias religiosas operadas por instâncias de Estado como as secretarias de turismo municipais, e a transformação das tradicionais romarias católicas em campos simbólicos de disputa entre os quais confluíam interesses da Igreja Católica, de Estado e de mercado. Em grande medida, essa análise situacional inspirava-se na crítica apresentada por McKevitt (1991) da utilização da dicotomia durkheimiana ${ }^{3}$ entre o "sagrado" e o "profano" para a análise da territorialidade agenciada nesses eventos.

Dentro dessa chave de interpretação, foi desenvolvido o meu trabalho de conclusão de curso em 2001, depois de trabalho de campo desenvolvido, em grande parte, no ano de 1999 e 2000. O TCC tinha como objeto empírico uma romaria criada a partir de uma relatada aparição de Nossa Senhora na cidade de Taquari, na região central do RS. Em 1988, crianças de uma escola da região rural dessa cidade passaram a se comunicar com uma santa que, diziam, aparecia numa árvore próxima à escola e à igreja que frequentavam. Em duas semanas, emergiu um modelo simbólico de longa duração relacionado a aparições de Nossa Senhora, colocado em risco dentro de um encontro complexo, no qual confluíram agentes religiosos católicos (os padres locais, a Diocese, a Renovação Carismática Católica) e não-religiosos (Prefeitura, jornais, revistas e canais de TV). Seguiram-se ao longo dos anos disputas pela interpretação legítima da aparição e pelo modelo de santuário a ser instaurado ali, nas quais carismáticos católicos vindos de Porto Alegre entraram em "rota de colisão" com os padres locais, de linha de atuação mais próxima à Teologia da Libertação e que estavam sofrendo pressão contínua da instituição católica para que "tomassem o controle" da situação. Em consequência disso tudo, ao longo dos anos, a comunidade local cindiu-se e os padres deslocaram os carismáticos para fora do epicentro da aparição (ALVES, 2001; STEIL; ALVES, 2003). Em Taquari, como em outros lugares nos quais se apresentavam confluências massivas católicas, chamou-nos a atenção o embate entre modelos de catolicismo (popular, institucional, libertador engajado e carismático) e as conjunções entre esses modelos e o estímulo ao consumo e ao turismo. Nas cidades do interior do RS, naquele momento, tal

\footnotetext{
${ }^{3}$ Para a utilização dessa dicotomia no caso das peregrinações religiosas ver, por exemplo, Rosendahl (2002). 
estímulo econômico via religião era posto dentro da chave do "desenvolvimento regional".

A formação antropológica na graduação propiciou a mim uma possibilidade de estranhar algo que me era familiar. Dos 15 aos 24 anos, eu militara como católico praticante junto a um grupo de jovens em minha cidade natal. Contudo, a situação que se descortinava a partir da reconstituição da formação daquele santuário em Taquari levoume a relativizar a abordagem racionalista da religião que à época eu advogava, e a perceber com clareza (e estranhar profundamente) a transição para o carismatismo católico, com ênfase no êxtase religioso, que muitos de meus amigos de meu grupo mais próximo estavam experimentando. Passei a sentir-me deslocado em meu grupo religioso pela conjunção de minha formação universitária com uma transformação no contexto em que vivia, e isso se acentuou quando, a partir de uma conversa informal com uma professora de antropologia (“Que tal você estudar uma religião que não tenha Deus?”), passei a desenvolver uma proposta para o mestrado que envolvia a pesquisa entre budistas.

O novo campo escolhido era em tudo diferente do campo de Taquari. O público que acorre aos centros budistas dedicados a converter brasileiros, via de regra, detém um nível de escolaridade superior completa ou incompleta e certo histórico de trânsito religioso depois do abandono da religião dos pais. A versão do budismo que presenciei ser comunicada a esses potenciais aderentes/convertidos em retiros espirituais apresentava doutrinas flexíveis e uma proposta de conhecimento de si. Embora planejasse fazer meu campo num famoso centro de budismo tibetano em Três Coroas (RS), meu projeto (que previa permanência na comunidade) foi recusado pelos condutores do templo, e assim acabei por fazer meu trabalho de campo num centro budista na grande Porto Alegre, o qual fundia práticas e ensinamentos do zen-budismo e do budismo tibetano. Essas duas linhagens budistas faziam parte da formação do condutor principal do Centro de Estudos Budistas Bodisatva (CEBB), um ex-professor universitário de física.

Nesse momento, interessei-me pelas maneiras de conversão/adesão religiosa num grupo de iniciantes no budismo que encontrava semanalmente no CEBB. Ao longo das conversas desses iniciantes em grupo, e depois, quando passei a entrevistá-los individualmente em suas casas, fui percebendo a impossibilidade de interpretar aquela 
conversão/adesão pelas chaves comumente idealizadas da conversão cristã, de completa transformação de si em função de uma nova opção religiosa. Existia, tanto entre praticantes mais antigos quanto entre os iniciantes, uma recusa em se dizer "budista" que era estimulada pela própria doutrina. Por outro lado, estimulava-se no CEBB uma releitura da trajetória de vida pessoal de acordo com os preceitos budistas. Contudo, essa refiguração da história pessoal em termos budistas era proposta dentro de uma continuidade, de acordo com as doutrinas budistas da "natureza búdica", da inexistência de uma essência no Eu e das sucessivas identidades, ou "reencarnações". Para ser sucinto, eu, enquanto cientista social, municiava-me de um conceito de "identidade religiosa" que não encontrava eco no conceito de "identidade budista" advogado pelos praticantes mais antigos, e apropriado com margens consideráveis de liberdade pelos mais novos. Em uma chave de interpretação de Paul Ricoeur, o conceito de identidade da antropologia clássica era mesmidade, o que se me apresentava, ipseidade. Esse problema, advindo do encontro etnográfico, era ignorado numa antropologia que dissolvia o conceito do nativo dentro do conceito antropológico de sujeito numa operação de tradução que transpunha a hierarquia colonial para dentro do texto etnográfico (ASAD, 1991).

Entre 2007 e 2011, dentro de um processo de escrita coletiva no qual derivaram três teses orientadas pelo professor Ari Pedro Oro (PPGAS-UFRGS), encontramos os meios para desenvolver um trabalho sobre transnacionalização religiosa em alguns países do MERCOSUl. Ao longo desse período, fomos descobrindo e esquadrinhando uma situação no meio evangélico que era vislumbrada apenas em uma de suas facetas. $\mathrm{Na}$ literatura das Ciências Sociais da religião, ao Sul do contnente latino-americano, vem sido identificada, desde o início dos anos 1990, o avanço de grandes denominações brasileiras no Uruguai e na Argentina, principalmente da Igreja Universal do Reino de Deus (BARRAGAN, 2006; MARDERO; BARRAGÁN, 2004; SEMÁN, 2003) e da Igreja Pentecostal Deus é Amor (PI HUGARTE, 1992; 1997). Porém, entre pastores e músicos pentecostais, líderes de pequenos empreendimentos religiosos em Porto Alegre e Montevidéu, identificamos uma influência de líderes argentinos, algumas vezes constituída por visitas mútuas e relações de amizade. Alguns desses líderes pentecostais argentinos de renome na região já tinham sua atuação caracterizada em estudos localizados (ALGRANTI, 2010; BELTRÁN; CANTO; FOSTIK; ROJIDO, 2005; WYNARCZYK, 1993) ou em avaliações extensivas acerca do campo a que pertencem (WYNARCZYK, 2009; WYNARCZYK; SEMÁN, 1994). Um terreno propício para um 
estudo de redes sociais transnacionais a partir de uma perspectiva metodológica multissituada (ALVES, 2011).

Desde a graduação, com minha vinculação ao Núcleo de Estudos da Religião (NER-UFRGS) e até o presente momento, explorei linhas de reflexão associadas às problemáticas em voga no meio, e que me permitem fazer uma recapitulação a partir desses temas. Embora o texto de Wright Mills mencionado na epígrafe deste texto assevere que tais recapitulações são tão proveitosas quanto mais longa for a carreira do investigador social, creio que um esforço analítico sobre meus interesses de pesquisa poderia trazer à luz encadeamentos elucidativos acerca do tipo de cientista social que me tornei.

\section{Secularização e modernas formas de crer}

Desde meus primeiros contatos com os debates na antropologia da religião, havia uma discussão que até o presente momento perdura, talvez hoje com menos teleologia e mais trabalho empírico que outrora. Trata-se do desenvolvimento de uma gama de conceitos weberianos sobre a modernidade religiosa no Ocidente, conhecida pela chave teórica da secularização. Supunha-se que, com a crescente separação das sociedades em esferas sociais autônomas e a ascensão do individualismo, a religião, antes fonte monopólica de valores sociais (BERGER, 1985), fosse deslocada para o terreno da decisão pessoal ou mesmo deixasse de ter importância central na vida das pessoas.

Separação de esferas de valor autônomas e individualismo vigentes, observou-se um cenário que parece ter surpreendido os "modernos", ou seja, os que crêem na modernidade (LATOUR, 1994) e, consequentemente, no Deus ausente do mundo. "Que ciência seria essa, cuja principal descoberta consistiria em fazer desaparecer o mesmo objeto de que trata?" (DURKHEIM, 1996, p. 68). O questionamento de Émile Durkheim, direcionado no momento da publicação de As formas elementares de vida religiosa à interpretação marxista da religião, é como um fantasma que ronda os neo-weberianistas que tomaram a secularização como uma profecia autorrealizável nos tempos áureos da crença no progresso pela dominação tecnocrática e no welfare state ao estilo europeu, entre os anos 1960 e 1970. O que se observou, ou passou a ser observado, a partir dos anos 1980, é que a religião estava lá, e bem. A secularização estaria perdendo espaço? Teria o anti-modernismo retornado, na forma de pensamento mágico ou religião? $\mathrm{Ou}$ ainda: alguma vez a religião se foi? Nos últimos dez anos, os analistas da religião que 
tomavam a secularização como profecia hoje promovem "reformas" analíticas que procuram manter o poder explicativo da teoria e, por outro lado, a coerência entre o pensado e o observado (BERGER, 2001).

Trabalhando como pesquisador nessa área, poderia falar, sim, de uma crise de confiança nas instituições religiosas aguçada pelo individualismo, embora esse individualismo pareça muito diferente do modelo do "asceta intramundano" (WEBER, 2004). Para além das doutrinas, esse contexto sociológico era um dos fatores que torna tão difícil a afirmação peremptória da identidade religiosa para um dedicado budista de classe média, por exemplo (ALVES, 2006). Muitos ali preferiam pensar o budismo como filosofia de vida, não como religião. Fui encontrar, com outro significado, o mesmo significante noutro contex to bem diferente. Um evangelista pentecostal argentino, Carlos Annacondia, bastante consciente das desconfianças à religiões institucionalizadas, afirmava abertamente em suas campanhas nas praças públicas que "a religião não pode fazer nada pelo homem, só Jesus pode". Essa "recusa da religião" entre os pentecostais não é, em termos teológicos, novidade. Contudo, a despeito dessa convicção, a campanha desse evangelista argentino visava trazer novos conversos para igrejas pentecostais locais que lhe davam suporte para aquela campanha.

Tanto nos circuitos new age, do qual o público que acorre ao budismo participa, quanto nas religiosidades pentecostais, a experiência religiosa individual vem primeiro que a doutrina na ordem das prioridades. Em ambas, vigoram crenças acerca do poder das palavras proferidas como cerne da experiência religiosa: a expressão oral e corporal do favorecimento desejado (prosperidade, saúde, harmonia) é a primeira condição para que esse favorecimento se materialize. Entretanto, se quisermos enfatizar as diferenças entre modelos ideais de pessoa (MAUSS, 1974b), podemos considerar que, nos circuitos new age, o self refigura-se continuamente ao longo de diversas experiências de autoconhecimento, enquanto que, no pentecostalismo, mais de acordo com o modelo de conversão cristã, roga-se para que um poder divino interfira e transfigure o sujeito, transformando-o completamente.

A psicologização da religião, promovida pelos circuitos de prática new age ${ }^{4}$ e pelas práticas de cura divina pentecostais e carismáticas, ${ }^{5}$ e a ênfase das confissões

\footnotetext{
${ }^{4}$ Ver Amaral (2000) e Sanchis (2001, p. 33).

${ }^{5}$ Ver, para o caso do catolicismo carismático, Silveira (2014). REVISTARELEGENSTHRÉSKEIA - 2019 - UFPR
} 
pentecostais na utilização das mídias de informação, alteraram as formas de sensibilidade religiosa em todo o espectro de opções disponíveis, ao menos no Brasil. Sob tudo isso, como um "bajo contínuo", para mencionar a metáfora musical que dá pertinente título ao livro de Semán (2006), está a estrutura dinâmica e sincrética da cultura (SANCHIS, 1994; 2001), que atua como uma sintaxe produtiva em contínua bricolage simbólica perceptível, pensando numa longa duração, no catolicismo popular (STEIL, 1996). A incidência do fenômeno dos processos de globalização e das correntes migratórias contemporâneas complexifica ainda mais o cenário religioso atual, que, como vimos, era tido como em retração em sua importância para as subjetividades individuais e em sua visibilidade pública, até duas décadas atrás.

\section{Recompondo associações e redefinindo identidades: religião, mercado, espetáculo, mídia e política}

A despeito do lugar que os modernos gostariam de reservar à religião, ela se torna cada vez mais expressão pública, e suas porções mais dinâmicas afetam diferentes dimensões da vida social. Arrolarei, em tópicos, certas intersecções que me fizeram pensar ao longo dos anos, e que continuam a ser pontos de reflexão:

Religião, mercado e consumo. A multiplicação de mediadores de simbologias religiosas tem levado a uma espécie de "comoditização". Utilizando essa palavra, não faço nenhum juízo de valor, mas identifico a partir dela processos que envolvem religião e mercado que não eram comuns há alguns anos. Peregrinações religiosas são cada vez mais estimuladas por agentes governamentais interessados no desenvolvimento regional pelo turismo religioso. As editoras seculares já se deram conta, a partir do sucesso de livros como os de Paulo Coelho e do Dalai-Lama, que livros com temáticas religiosas possuem grande potencial comercial. Gravadoras seculares, como a Sony Music e a Som Livre (das Organizações Globo), alavancaram-se nos últimos anos como expoentes do mercado de música gospel e na divulgação de padres cantores brasileiros. O faturamento anual do segmento gospel estava estimado em 2011 em 500 milhões de reais, com público fiel e taxas relativamente baixas de pirataria.

Religião, mídia e espetáculo: no segmento pentecostal e, em menor medida, no meio carismático católico, tornou-se comum a utilização de recursos baseados nas modernas tecnologias de informação (digitais e via Internet), inclusive para fins rituais, com "cultos à distância" e assessoria pastoral via Skype (ALVES, 2011). Instauraram-se 
novas formas de criar immediacy (MEYER, 2011), utilizando os meios tecnológicos necessários para que esses mesmos meios “desapareçam” juntamente com as distâncias, levando não apenas a mensagem, mas também o êxtase divino mais longe. Ao mesmo passo em que novas formas de interação surgem, a ligação da religião com a linguagem dos espetáculos massivos se intensifica. Entre católicos carismáticos, há os rebanhões e cenáculos; do lado evangélico, campanhas de evangelização de massa e festivais abertos que crescentemente incluem atrações do mundo secular, sem falar em todo um mercado de "conferências" (em verdade, sequências de cultos que podem durar alguns dias) promovido por igrejas de todos os tamanhos, que divulgam a vinda de pregadores de renome em cenários evangélico-pentecostais regionais ou internacionais.

Religião, política e ação social: as estratégias de visibilidade pública dos grupos religiosos passam por caminhos diversos. Alguns desses meios de relacionar-se com o mundo entre os evangélicos pentecostais envolvem incursões pela política formal, na tentativa (quase sempre mal-sucedida, no Brasil) de apresentar-se como "último bastião moral” da República (MACHADO, 2006; MARIANO; HOFF; DANTAS, 2006; ORO, 2003; SANTOS, 2005). Procuram-se ainda formas de aumentar tal visibilidade pública através da "ação social” voltadas a problemas das comunidades, num misto de ação social voluntária e proselitismo religioso que fazem surgir fundações, casas de atendimento a situações de vulnerabilidade social das mais diversas, e iniciativas de relação com a comunidade circundante.

Sobre os pressupostos epistemológicos em torno ao tema "religião, mídia e consumo"

Desde o momento que assumi o cargo de professor, pesquisador e extensionista no então Campus Catalão da Universidade Federal de Goiás e até o presente momento, tanto as discussões e as condições do trabalho acadêmico quanto a realidade social do país e das religiões mudaram muito, e rápido. Com outra posição no campo, passei a orientar discentes que com frequência se deparavam com formas rituais, de pertencimento e crença realmente desafiadoras. Nos últimos anos, tenho desenvolvido pesquisas sobre o tema "religião e consumo", preocupado especialmente com as modalidades de objetificação dos bens de marcação religiosa (ALVES, 2019a; b).

Alguns temas vêm despertando um misto de desafio epistemológico e, pela falta de palavra mais adequada em 2020, angústia. Por um lado, temos as contínuas redefinições internas das simbologias e ritualismos das religiões por conta de suas 
comunicações mútuas. Por outro, percebe-se o desbordamento dos contornos "modernos" da política pelas religiões, especialmente por parte de um pentecostalismo de caráter triunfalista e militante. Num deles, o alvo do desafio epistemológico reside na definição de religião; no outro, analisa-se, lamenta-se e/ou enfrenta-se a contínua redefinição dos limites entre o campo das religiões, a sociedade e a política.

Nenhum desses temas é novo. O primeiro faz parte da dinâmica dos repertórios simbólicos profundamente enraizados na memória coletiva (no Brasil, figuram como as "matrizes" católica, afro-brasileira e mediúnica). Quanto as relações entre religião e política, já foi observado mais de uma vez que os evangélicos pentecostais não inauguraram as imbricações entre identidades, crenças, símbolos e práticas da religião e do poder, nem no Brasil, nem em lugar algum. E exatamente por não serem novidade que esses fenômenos merecem toda a atenção dos estudiosos. Eventos localizados por vezes merecem ser vistos como epifenômenos, assim como pequenos tremores de terra anunciam movimentos mais profundos, nem sempre percebidos no calor dos sucessivos eventos à superfície. A mesma perspectiva, a nosso ver, vale para a interpretação de eventos relacionados à política e à sociedade no Brasil.

Nas relações entre religião, consumo e espetáculo no meio evangélico pentecostal, especialmente nas formas mais avivadas, é possível perceber uma totalização do sentimento de pertencer que abre a possibilidade para tomadas de posição e visões de mundo que vão para além do campo da crença ou das práticas religiosas, que desembocam por vezes em posições políticas direcionadas a si e aos outros, ligadas a, e justificadas por, outras formas de extremismo. Outra vez, nada de novo há aqui. Bastaria um pouco de leitura sobre o avanço das religiões monoteístas no Ocidente para perceber que algumas formas de sua expansão passam pela dinâmica que explicitamos acima. Só que nada é tão simples. Especialmente no terreno da radicalização política do evangelismo pentecostal, temos uma confluência de elementos realmente novos (a democratização da comunicação e da opinião por via digital, por exemplo).

Buscamos algumas dessas pistas de movimentos mais profundos nas relações entre religião, consumo e espetáculo no meio evangélico pentecostal. Houve tempos em que a corrente hegemônica dentro do mundo pentecostal rechaçava os princípios da sociedade de consumo no Brasil (FRESTON, 1994; MARIANO, 2005), contudo hoje o que vemos é algo bem diferente disso. Entre esses princípios, referimo-nos em específico 
à capacidade do capital em criar novas necessidades de consumo incessantemente. Ao entendimento da natureza desse mecanismo, ou do sentido dessa relação social, dedicaram-se a teoria da alienação em Marx (1968) e a chamada Escola de Frankfurt ou teoria crítica (ver especialmente MARCUSE, 1964). Esse também é o ponto de partida para Campbell (2001), quando examina o enquadramento dos economistas sobre as origens do comportamento do consumidor.

O que acontece quando uma religião, antes refratária ao "mundo" e ao consumo conspícuo, passa a criar ou atender necessidades de consumo nos terrenos da moda, do livro, da música e do espetáculo? Em qual medida e sentido tais necessidades de consumo ligam-se a necessidades religiosas? Arremessando essas questões ao campo: será que se pode curar ou salvar as almas ouvindo músicas, assistindo a vídeos no Youtube ou canais de TV, indo a shows, vestindo roupas, partilhando um universo de referências e bens? Voltando à teoria: quais os efeitos socioculturais da explosão dessa oferta de mediações ao sagrado nas representações e atitudes de sujeitos concretos? Essas são perguntas que viemos nos fazendo nos últimos anos, e todas, a nosso julgar, encontram eco em problemáticas caras à sociologia e à antropologia desde seus primórdios.

Quais os obstáculos epistemológicos principais nesse terreno? São os efeitos de evidência, a negação do espelhamento e o reducionismo. O primeiro desses efeitos diz respeito à generalidade do fenômeno. Não é necessário muito esforço para juntar farto material, nas mídias e nas compras de bens, que ateste o investimento na comunicação e no consumo para a divulgação de mensagens religiosas. Ultimamente, aliás, o problema tem sido construir objetos definidos dentro das possibilidades de observação. A simples coleção de itens ou de material de comunicação religiosa, em massa, sem critério ou com critérios frágeis, atesta que tivemos contato com esses materiais, mas não resolve em si a construção do objeto de reflexão.

E dentro da ideia da construção do objeto, um dos elementos fundamentais é o de romper com os objetos óbvios impostos como problemática pelo próprio campo religioso e pela "sociologia espontânea" dos telejornais, das colunas de opinião e, mais que tudo, do etnocentrismo ou sociocentrismo do próprio observador.

O sociólogo nunca conseguirá acabar com a sociologia espontânea e deve se impor uma polêmica incessante contra as evidências ofuscantes que proporcionam, sem grandes esforços, a ilusão do saber imediato e 
de sua riqueza insuperável

(BOURDIEU; PASSERON; CHAMBOREDON, 1999, p. 23)

A análise da pluralização de formas midiáticas que os agentes religiosos levam adiante não pode simplesmente ignorar o fato de que quase toda comunicação é midiatizada, inclusive a do observador. Falas, escritas e imagens chegam aos sentidos por veículos. Nas sociedades modernas, as interações diretas não veiculadas constituem uma fração muito pequena da comunicação existente, e mesmo nessas estamos comentando informações que nos chegaram por mídias acerca do clima, do futebol, da política e da religião. Disso deriva que boa parte dos problemas que entendemos como "os problemas reais" de nosso interesse social ou político pautam-se pelo que chega a nós por mídias. O enraizamento da ideia de Estado-Nação no Século XIX, por exemplo, dependeu da existência de uma imprensa que tornasse ao leitor uma espécie de partícipe virtual dos problemas nacionais (HERZFELD, 1997). Parece no mínimo algum tipo de "centrismo" alegar que os sujeitos que seguem a grupos religiosos arrastam sua atenção de forma midiatizada, sem a devida crítica às mediatizações que fizeram surgir os objetos do próprio sujeito que pesquisa. Simplesmente ancorar os dados em metodologia de observação participante não resolve em absoluto o "problema do Barão de Müncchausen" (LÖWY, 1994), sobre como alguém sobre um cavalo atolado na lama consegue arrancar a si mesmo e ao cavalo puxando os próprios cabelos. Ou, em outras palavras, como alguém imerso nos seus sistemas de categorias socioculturais pode falar de um outro mundo sociocultural "objetivamente". Se a ruptura iluminista para o conhecimento do social foi a crítica da religião ("é o pressuposto de toda a crítica"; MARX, 2010, p. 29), o primeiro embate do e da cientista social hoje é exercer uma anamnese constante da sua "bolha" midiatizada por redes sociais, vídeos de internet, livros e matérias de jornal. ${ }^{6}$

\section{Conclusão}

Ao longo deste texto, evidenciei a trajetória de reflexão sobre as religiões que me levou até o presente momento. Ao abordar essa trajetória, intentei perceber como as experiências de campo exigiram um retrabalho de conceitos ou concepções que faziam parte de meu repertório. Após isso, desenvolvi uma série de observações sobre os desafios epistemológicos que se apresentam aos que pretendem estudar as relações entre consumo, mídia e religião, em chaves de questionamentos que seguem, se vistas num plano amplo,

\footnotetext{
${ }^{6}$ Para discussões bastante pertinentes sobre essas possibilidades e limites de análise no campo da religião, do consumo e da mídia, ver especialmente Algranti (2013; 2018) e Semán (2006; 2013). REVISTARELEGENSTHRÉSKEIA - 2019 - UFPR
} 
os primeiros movimentos que levaram à minha formação. Se toda religião é mediação, e se a comunicação nas sociedades contemporâneas é midiatizada, a midiatização da religião não deveria ser encarada como algo novo ou excêntrico. Exatamente por isso, a comunicação que veicula mensagens religiosas por vezes revela movimentos profundos nas relações entre religião e sociedade.

Os "pontos de intersecção" mencionados ao centro do texto, mais do que simples constatações de causas religiosas e seus efeitos para além da religião, fazem parte de um esforço intelectual de recomposição. O intelecto humano é pródigo em estabelecer distinções estruturadas, e no caso do pensamento Ocidental, distinções entre saberes acadêmicos entre áreas e sub-áreas construíram-se como se a matéria sobre a qual o pensamento se projeta não interligasse continuamente toda sorte de fatores tomados por isolados dentro de um ponto de vista analítico formal. A antropologia, desde o princípio do século passado, estudou formas culturais cujas distinções intelectuais complexas não deram forma a saberes segmentados, e aprendeu com elas. A noção de "fato social total", construída por Marcel Mauss (1974a) ao longo do "Ensaio sobre a dádiva", é uma chave epistêmica fundamental para a percepção do enfeixamento de fenômenos ditos "científicos", "sociais" ou "econômicos" em situações concretas. Projetos de teoria antropológica recente, como as reflexões sobre poder e agency (ORTNER, 2006) ou a teoria do ator-rede (LATOUR, 2008), apenas para mencionar alguns dos mais conhecidos, permitem traçar associações inesperadas e redimensionar a capacidade criativa dos atores sociais.

Essa ênfase nos interstícios alimenta o artesanato intelectual antropológico continuamente. O desafio, quando se estuda as sociedades ditas "complexas", é encontrar e enquadrar teoricamente os fios que interligam sujeitos, valores (morais e econômicos), objetos, imagens, discursos, desigualdades e poder. A dádiva apresenta-se como um desses fios, mesmo nas sociedades modernas (GODBOUT, 1999). Outro liame possível, acerca do qual reflito atualmente a partir de meu trabalho com pentecostais, seria o êxtase. Práticas extáticas sempre foram conhecidas no mundo Ocidental, sendo reservadas sempre ao extramundano: a outras culturas, a santos católicos e aos espaços dos monastérios ou dos manicômios, até que foram reabilitadas no cristianismo, no princípio do Século XX, a partir do movimento pentecostal e seu distanciamento relativo da ascese do protestantismo histórico. Com isso, o cristianismo passou a dialogar com a linguagem do espetáculo, tendo influência, inclusive, no início da história do rock'n roll como estilo 
musical, no período posterior à Segunda Guerra Mundial. Com o desenvolvimento do rock como movimento de efervescência cultural, abriu-se o espaço para que, durante os anos 1960, houvesse uma pluralização das referências acerca do êxtase, adaptadas das religiosidades orientais e indígenas e estimuladas por experimentalismos narcóticos e sexuais. Tais experimentalismos, inicialmente cultivados em experiências comunitárias, gradativamente ao longo das décadas seguintes foram adquirindo tonalidades mais individualistas e comoditizadas, estimulando o surgimento de novos segmentos industriais voltados à distribuição de entretenimento de massas. Pelas voltas do destino, hoje os estilos de gospel music absorvem influências do rock, e também de muitos outros estilos musicais.

Esses temas enfeixariam uma ampla gama de trabalhos de campo, envolvendo conhecimentos, estéticas e sistemas simbólicos diversos. Além disso, envolveria o estudo de formas de produção, distribuição e circulação de bens culturais para além da religião, objeto de estudo que tem caracterizado minha trajetória até aqui. Compreendo, à maneira de Mauss, que há maneiras de fazer a reflexão gravitar em torno de problemáticas teóricas mais amplas, no sentido de elucidar processos culturais complexos em desenvolvimento no mundo contemporâneo.

\section{Referências bibliográficas}

ALGRANTI, J. Política y religión en los márgenes: nuevas formas de participación social de las mega-iglesias evangélicas en la Argentina. Buenos Aires: CICCUS, 2010.

Aires: Biblos, 2013.

(org.). La industria del creer. Sociología de las mercancías religiosas. Buenos

Produzir o Extraordinário: objetos, rituais e carisma na vida religiosa urbana. Religião e Sociedade, 38, n. 1, p. 159-180, 2018.

ALVES, D. Do surgimento e trajetória de um santuário mariano: visões, imagens e mensagens de Nossa Senhora em Taquari. 2001. Trabalho de conclusão (Graduação em Ciências Sociais - Instituto de Filosofia e Ciências Humanas, UFRGS, Porto Alegre.

$57-80,2006$.

Notas sobre a condição do praticante budista. Debates do NER (UFRGS), v. 7, p.

Conectados pelo Espírito: Redes de contato e influência entre líderes carismáticos e pentecostais ao Sul da América Latina. 2011. Tese (Doutotado em Antropologia Social) - Programa de Pós-Graduação em Antropologia Social, Universidade Federal do Rio Grande do Sul, Porto Alegre.

Imagens, bíblias, bandas e favas: o mercado de bens de marcação religiosa em Catalão, Brasil. Mitológicas, XXXIV, p. 9-34, 2019a.

Para a análise sociocultural do mercado de bens com marcação religiosa: marcos teóricos da pesquisa. Sociedad y Religión, 19, n. 51, p. 174-186, 2019 b. 
AMARAL, L. Carnaval da alma: comunidade, essência e sincretismo na nova era. Petrópolis: Vozes, 2000.

ASAD, T. El concepto de la traduccion cultural en la antropologia social britanica. In: CLIFFORD, J. e MARCUS, G. E. (Orgs.). Retoricas de la Antropologia. Madrid: Jucar Universidad, 1991. p. 205-234.

BARRAGAN, Y. R. A Igreja Universal do Reino de Deus no Uruguai: Um estudo antropológico sobre narrativas. 2006. Dissertação (Mestrado em Antropologia Social) PPGAS, UFRGS, Porto Alegre.

BELTRÁN, A.; CANTO, S.; FOSTIK, A.; ROJIDO, E. El disciplinamiento en la conformación del ser religioso de la Iglesia Misión Vida para las Naciones. In: FILARDO, V. (Org.). Religiones alternativas en el Uruguay. Montevideo: Universidad de la República Oriental del UruguayFacultad de Ciencias Sociales, 2005. p. 27-48.

BERGER, P. L. O dossel sagrado. São Paulo: Paulinas, 1985. (Coleção Sociologia e Religião; 2. p. 9-24, 2001.

. A dessecularização do mundo: uma visão global. Religião e Sociedade, 21, n. 1,

Bourdieu, P.; PASSERON, J.-C.; CHAMBOREDON, J.-C. A Profissão de Sociólogo: pressupostos epistemológicos. Petrópolis: Vozes, 1999.

CAMPBELL, C. A ética romântica e o espírito do consumismo moderno. Rio de Janeiro: Rocco, 2001. 31-56 p.

DURKHEIM, É. As Formas Elementares da Vida Religiosa. São Paulo: Martins Fontes, 1996. (Coleção Tópicos).

FRESTON, P. Breve história do pentecostalismo brasileiro. In: ANTONIAZZI, A. e. $a$. (Org.). Nem anjos nem demônios: interpretações sociológicas do pentecostalismo. Petrópolis-RJ: Vozes, 1994. p. 67-159.

GODBOUT, J. T. O Espírito da Dádiva. Rio de Janeiro: Fundação Getúlio Vargas, 1999.

HERZFELD, M. Cultural intimacy: social poetics and the nation-state. London, New York: Routledge, 1997.

LATOUR, B. Jamais Fomos Modernos. Rio de Janeiro: Editora 34, 1994. (Coleção Trans.

LATOUR, B. Reensamblar lo social: una introducción a la teoría del actor-red. Buenos Aires: Manantial, 2008.

LÖWY, M. As Aventuras de Karl Marx contra o Barão de Münchhausen: marxismo e positivismo na sociologia do conhecimento. 5 ed. São Paulo: Cortez, 1994.

MACHADO, M.D. Política e Religião : A participação dos evangélicos nas eleições. Rio de Janeiro: Fundação Getúlio Vargas, 2006.

MARCUSE, H. A ideologia da sociedade industrial: o homem unidimensional. 4 ed. Rio de Janeiro: Zahar, 1964.

MARDERO, N. G.; BARRAGÁN, Y. R. Más allá del bien y del mal: la Iglesia Universal del Reino de Dios en Uruguay. In: GEYMONAT, R. (Org.). Las religiones en el Uruguay: algunas aproximaciones. Montevideo: La Gotera, 2004. p. 130-145.

MARIANO, R. Neopentecostais: sociologia do novo pentecostalismo no Brasil. São Paulo: Loyola, 2005. 
MARIANO, R.; HOFF, M.; DANTAS, T. Y. S. Evangélicos sanguessugas, presidenciáveis e candidatos gaúchos: A disputa pelo voto dos grupos religiosos. Debates do NER, 6, n. 10, p. 6578, 2006.

MARX, K. O Capital: Crítica da Economia Política. Rio de Janeiro: Civilização Brasileira, 1968.

Contribuição à crítica da filosofia do direito de Hegel. Introdução. São Paulo: Expressão popular, 2010.

MAUSS, M. Ensaio sobre a dádiva. In: Sociologia e Antropologia. São Paulo: EPU/EDUSP, 1974a. v. 2.

Uma categoria do pensamento humano: a noção de pessoa, a noção de 'eu'. In: MAUSS, M. (Org.). Sociologia e Antropologia. São Paulo: EPU/EDUSP, 1974b. v. 1, p. 207240.

MCKEVITT, C. San Giovanni Rotondo and the Shrine of Padre Pio. In: EADE, J. e SALLNOW, M. J. (Orgs.). Contesting the Sacred: the Antropology of christian pilgrimage. Londres; Nova York: Routledge, 1991.p. 77-97.

MEIRELLES, M.; ALVES, D. Somos todos iguais? Religião e renda no Censo 2010. Horizonte: Revista de Estudos de Teologia e Ciências da Religião, 10, n. 28, p. 1184-1207, 2012.

MEYER, B. Mediation and immediacy: sensational forms, semiotic ideologies and the question of the medium. Social Anthropology/Anthropologie Sociale, 19, n. 1, p. 23-39, 2011.

ORO, A. P. Igreja Universal: um poder político. In: ORO, A. P. et al (Orgs.). Igreja Universal do Reino de Deus. Os novos conquistadores da fé. São Paulo: Paulinas, 2003. p. 281-302.

ORTNER, S. Power and projects: reflections on agency. In: Anthropology and Social Theory: culture, power and the acting subject. Durham/London: Duke University Press, 2006. p. 129153.

PI HUGARTE, R. La Iglesia Pentecostal "Dios es Amor" en el Uruguay. Cadernos de Antropologia, n. 9, p. 62-96, 1992.

Transnacionalização da religião no Cone Sul: o caso do Uruguai. In: STEIL, C. A. e ORO, A. P. (orgs.). Globalização e Religião. Petrópolis: Vozes, 1997. p. 201-218.

ROSENDAHL, Z. Espaço e religião: uma abordagem geográfica. 2 ed. Rio de Janeiro: UERJ, 2002.

SANCHIS, P. Para não dizer que não falei de sincretismo. Comunicações do ISER, 45, p. 4-11, 1994.

Religiões, religião... Alguns problemas do sincretismo no campo religioso brasileiro. In: Fiéis e cidadãos: percursos do sincretismo no Brasil. Rio de Janeiro: EdUERJ, 2001. p. 9-57.

SANTOS, M. M. Tribunos do povo, servos de Deus : um estudo antropológico sobre políticos e religião na cidade de Porto Alegre. 2005. Disssertação (Mestrado em Antropologia Social) Programa de Pós-Graduação em Antropologia Social, Instituto de Filosofia e Ciências Humanas, Universidade Federal do Rio Grande do Sul, Porto Alegre.

SEMÁN, P. A Igreja Universal na Argentina. In: ORO, A. P.;CORTEN, A., et al (Orgs.). Os novos conquistadores da fé. São Paulo: Paulinas, 2003. p. 69-78.

Bajo continuo: exploraciones descentradas sobre cultura popular y massiva.

Buenos Aiires: Gorla, 2006. p. 35-60. 
Introducción. In: ALGRANTI, J. (Org.). La industria del creer. Sociología de las mercancías religiosas. Buenos Aires: Biblos, 2013.

SILVEIRA, E. J. S. Catolicismo, Mídia e Consumo. São Paulo: Fonte Editorial, 2014.

STEIL, C. A. O Sertão das Romarias. Petrópolis: Vozes \& CID, 1996.

STEIL, C. A.; ALVES, D. 'Eu sou a Nossa Senhora da Assunção'. A aparição de Maria em Taquari, Rio Grande do Sul. In: STEIL, C. A. et al (Orgs.). Maria entre os vivos: reflexões teóricas e etnográficas sobre aparições marianas no Brasil. Porto Alegre: Editora da UFRGS, 2003. p. 175-203.

WEBER, M. A Ética Protestante e o "Espítrito" do Capitalismo. São Paulo: Companhia das Letras, 2004.

WRIGHT MILLS, C. A imaginação sociológica. Rio de Janeiro: Zahar, 1975.

WYNARCZYK, H. Carlos Annacondia: un estudio de caso en neopentecostalismo. In: FRIGERIO, A. (Org.). Nuevos Movimientos Religiosos y Ciencias Sociales. Buenos Aires: Centro Editor de América Latina, 1993. v. 2, p. 80-97. (Los fundamentos de las Ciencias del Hombre).

Ciudadanos de dos mundos: el movimiento evangélico en la vida pública argentina 1980-2001. Buenos Aires: UNSAM Edita, 2009. (Ciencias Sociales).

WYNARCZYK, H.; SEMÁN, P. Campo evangélico y pentecostalismo en la Argentina. In: FRIGERIO, A. (Org.). El pentecostalismo en la Argentina. Buenos Aires: Centro Editor de América Latina, 1994. p. 29-43. 